\title{
A ABORDAGEM DE ALGUNS NÚMEROS IRRACIONAIS NOTÁVEIS NOS LIVROS DIDÁTICOS DO ENSINO FUNDAMENTAL E MÉDIO
}

\author{
THE APPROACH OF IRRATIONAL NUMBERS SOME REMARKABLE IN \\ TEXTBOOKS OF ELEMENTARY AND HIGH SCHOOL
}

\author{
Wagner Marcelo Pommer (USP) \\ wmpommer@usp.br \\ Clarice P. C. R. Pommer (USP) \\ claricepommer@usp.br
}

\begin{abstract}
Resumo
Este texto descreve os resultados de uma pesquisa orientada pela questão 'Como são abordados os números irracionais no ensino básico, considerando-se como fonte o livro didático?'. Em uma amostra de livros didáticos, observamos se e como são apresentados 'o número PI', 'o número de Euler' e 'o número de Ouro'. A investigação utilizou os núcleos de significação para analisar os sentidos do discurso presente nos textos dos livros didáticos. Constatamos que os temas apontados são introduzidos por um viés empírico ou pela definição formal, porém não ocorre intercâmbio destes pólos. Observamos que o número PI é empiricamente abordado, o número de Euler é apenas citado como uma possível base dos logaritmos e fica destaca a interface artística do número de Ouro articulada a representação algébrica. Em síntese, esta opção dos livros didáticos reforça uma concepção tecnicista, limitando a compreensão da complexidade dos números irracionais no Ensino Fundamental e Médio.
\end{abstract}

Palavras-chave: Livro Didático. Núcleos de Significação. Número PI. Número de Euler. Número de Ouro.

\begin{abstract}
This paper describes the results of a survey directed by the question 'How are discussed irrational numbers in primary education, considering the textbook as a source?'. In a sample of textbooks, if observed and are presented as 'the number PI', 'Euler number' and 'number of Gold'. The research used the nuclei of significance to analyze the meaning of discourse in the texts of textbooks. We note that the themes are highlighted by a bias introduced by empirical or formal definition, but there is exchange of these poles. We observed that the number PI is empirically approached, the number of Euler is only mentioned as a possible base of logarithms and highlights the interface is the number of artistic Gold articulated the algebraic representation. In summary, this option of textbooks reinforces a technicist conception, limiting the understanding of the complexity of irrational numbers in elementary and high school.
\end{abstract}

Keywords: Textbook. Nuclei of Meaning. PI number. Euler number. the Golden Mean.

\section{Introdução}

Em grande parte dos tópicos desenvolvidos no ensino de Matemática há predominância da concepção dos números como ferramenta operatória para cálculos de natureza aritmética e em manipulações de expressões algébricas. Porém, o ensino dos números e das operações: 


\section{INTERFACES DA EDUCAÇÃO}

[...] na educação básica não deve visar [somente] a aquisição de um conjunto de técnicas rotineiras, mas também uma aprendizagem significativa ligada a uma compreensão relacional das propriedades dos números e das operações. Não basta aprender procedimentos, é necessário transformá-los em instrumentos de pensamento (ABRANTES; SERRAZINA; OLIVEIRA, 1999, p. 47 apud COELHO, 2005, p.29).

A tendência tecnicista inserida na escolaridade remonta a raízes longínquas. Os povos antigos como os babilônios, chineses, egípcios e hindus utilizam os números numa concepção utilitária, ligadas a aspectos do mundo pragmático.

Para estes povos não fazia sentido haver distinção entre o exato e aproximado em relação aos cálculos numéricos. Em particular, os hindus foram os primeiros povos a:

[...] considerar as raízes irracionais como números. [...] Mas é preciso lembrar que a contribuição hindu nesse caso foi resultado de inocência lógica. Vemos a ausência de distinção cuidadosa, da parte dos matemáticos hindus, entre resultados exatos e inexatos e era natural que não levassem a sério a diferença entre grandezas comensuráveis e incomensuráveis (BOYER, 1991, p. 160).

Diferentemente dos demais povos antigos, os gregos concebiam os números inteiros como entidades abstratas. Em particular, ao estudar a relação entre a diagonal e o lado do quadrado, os pitagóricos perceberam que estes segmentos não são comensuráveis. Dois segmentos são ditos incomensuráveis se a razão entre estes não puder ser expressa como uma fração de números inteiros (com denominador não-nulo).

A constatação da impossibilidade de expressar alguns números como razão entre inteiros representou um momento de abalo, que posteriormente foi denominado por historiadores modernos como 'A crise dos incomensuráveis'.

Diante desse impasse entre a crença dos números inteiros e o problema da incomensurabilidade entre a diagonal e o lado do quadrado, a solução encontrada pelos antigos gregos foi utilizar a Álgebra Geometria: os números irracionais seriam expressos por segmentos de reta, mas não eram considerados números.

Assim, ao invés de desvendar o mistério envolvendo este 'novo número', a crença nos números inteiros impeliu os gregos a rejeitar e ocultar os números irracionais, por meio da Geometria. Deste modo, para os gregos:

[...] todo número podia ser expresso por um comprimento, mas existiam comprimentos que não correspondiam a nenhum número. [...] Jamais o [número] irracional teve na Grécia o valor de um número, e os gregos não possuíam símbolo para esta espécie de grandeza (KARLSON, 1961, p. 104).

Situando o marco representado pela 'Crise dos Incomensuráveis', os números irracionais permaneceram marginalizados e incompreendidos na Matemática. Foi somente após muitos séculos que a relação entre a diagonal e o lado de um quadrado foi representada pelo símbolo $\sqrt{2}$.

Contrariamente aos números racionais, cujo entendimento perpassa o pragmático, os números irracionais representam um elemento complexo e pouco intuitivo. No ensino da 


\section{INTERFACES DA EDUCAÇÃO}

Matemática Elementar, a característica teórica coloca os números irracionais numa posição problemática, que precisa ser mapeada.

Existe uma concepção falsa, até defendida por pesquisadores, destacando que a introdução dos números irracionais deve pressupor uma:

[...] completa compreensão dos números racionais pelos alunos. Entretanto, se isto não é alcançado ainda (como frequentemente ocorre), os alunos estarão enfrentando muitas dificuldades para abordar este novo tipo de número.

(VOSKOGLOU; KOSYVAS, 2011, p. 129).

Diante de tais ponderações, nos propusemos a verificar como alguns temas notáveis representantes dos números irracionais - o número PI, o número de Euler e o número de Ouro - são introduzidos, apresentados e desenvolvidos em uma amostra de livros didáticos.

\section{0 quadro teórico}

Observando-se os PCN, Brasil (1998) e a Proposta Curricular, São Paulo (2008) há menção que o trabalho com números irracionais no ciclo básico geralmente se encontra muito simplificado, geralmente se concentrando em cálculos operatórios com radicais e se limitando a apresentação de raízes inexatas e de PI.

O conhecimento envolvendo o conjunto dos números irracionais sofreu uma lenta elaboração ao longo de dois séculos, sendo resolvido e sistematizado pelos matemáticos há pouco mais de 100 anos. Este conhecimento adquirido através do movimento histórico sofreu uma transposição didática para ser ensinado em sala de aula.

Consideramos que os livros didáticos se constituem num importante meio para se observar como os saberes são apresentados e desenvolvidos no ensino básico. Na revisão bibliográfica efetivada, autores como Santos (2007), Boff (2007), Souto (2010), e Silva (2011a, b) apontam que a apresentação dos números irracionais geralmente enfoca situações pragmáticas, envolvendo a aproximação de resultados.

Uma exemplificação recorrente nos livros didáticos é "[...] a caracterização do número irracional $\pi$ partir de experiências relacionando o comprimento da circunferência de um objeto com seu diâmetro. Cabe ressaltar que esta abordagem, se não for tomado o devido cuidado, pode reforçar a atitude de identificar o número $\pi$ com uma de suas aproximações" (SANTOS, 2007, p. 63).

Em caminho oposto, certos manuais preferem a apresentação teórica, ora expondo um número irracional como sendo uma dízima não periódica, ora definindo como números irracionais como sendo os números reais que não podem ser expressos por meio de uma razão entre números inteiros.

A seguir, os manuais escolares introduzem os números reais como a união de dois conjuntos disjuntos: os números racionais e os números irracionais ( $R=Q \cup$ Irracionais). Rezende (2003) aponta aí o quadro da circularidade: quem são os números reais? Quem são os números irracionais?

Souto (2010) realizou pesquisa diagnóstica em livros didáticos, verificando que os livros didáticos privilegiam atividades com contexto tecnicista, com pouco ou nenhum aprofundamento conceitual. Os resultados apontados por Souto (2010), com relação à falta de um discurso racional e tecnológico que justifique e esclareça técnicas, procedimentos e 


\section{INTERFACES DA EDUCAÇÃO}

propriedades, se centra no conhecimento matemático já estabelecido. Ponderamos que para prover meios de tratar os números irracionais na escolaridade básica devem ser concebidos referenciais situados num ponto de vista teórico, que leve em consideração tanto o discurso presente na construção epistemológica do conhecimento matemático, quanto em aportes didáticos de ensino e de aprendizagem.

Considerando-se outra pesquisa, Silva (2011a) analisou livros didáticos de Matemática do Ensino Médio, com a finalidade de ilustrar o modo como os manuais apresentam o tema dos números reais. A referida autora observou que nos livros didáticos há predominância de valores prototípicos como $\sqrt{2}, \sqrt{3} e \pi$, geralmente abordados de modo sistematizado, o que limita o entendimento deste tópico, fato já referenciado nos PCN, Brasil (1998).

O universo numérico apresentado aos nossos estudantes pelos manuais escolares se restringe aos números racionais acrescido de um conjunto enumerável de pouquíssimos números irracionais notáveis, conforme aponta Rezende (2003).

Considerando pesquisas com alunos, Fischbein, Jehiam e Cohen (1995) constataram concepções errôneas na conceituação dos irracionais em estudantes concluintes da educação básica e licenciandos em Matemática, de Telaviv. A pesquisa de Ripoll (2001) destaca que alguns do $9^{\circ}$ ano do Ensino Fundamental erroneamente afirmam que $\sqrt{-1}$ é um número irracional, pois não pode ser escrito na forma de fração de números inteiros.

Em síntese, as pesquisas envolvendo o material didático destinado ao ensino básico evidenciaram alguns elementos, com foco nos conteúdos matemáticos, que contribuem em maior ou menor medida, para dificultar a aprendizagem. Ainda, os autores apontaram algumas estratégias locais, com base nos referenciais propostos, para encaminhar soluções.

Porém, as ponderações expressas nas análises realizadas pelos respectivos autores não permitem sintetizar um quadro geral e indicativo que possa compor um referencial para tratar tal temática no ensino básico de forma globalizada.

\section{O quadro metodológico para a análise nos livros didáticos}

Para a análise dos números irracionais a que nos propusemos fizemos uso dos denominados núcleos de significação, metodologia de pesquisa qualitativa voltada para a análise dos modos de manifestação de sujeito(s), que está descrita em Aguiar e Ozella (2006).

Esta metodologia foi inspirada na Psicologia Sócio-Histórica, tendo como objeto "[...] os procedimentos de análise de material qualitativo, visando a apreender os sentidos que constituem o conteúdo do discurso dos sujeitos informantes através do que chamamos de núcleos de significação" (AGUIAR; OZELLA, 2006, p.1).

No presente texto, utilizamos esta metodologia como um possível recurso de analisar o discurso exposto no livro didático, manifestado nos modos de exposição de conteúdos e propostas de encaminhamento didático presentes na obra, envolvendo os números irracionais.

Segundo Aguiar e Ozella (2006), os núcleos de significação fazem parte de um processo construtivo e interpretativo, devendo ser gerados por indicadores que expressem os pontos centrais e fundamentais da apresentação dos sujeitos.

Os autores ponderam que um primeiro critério para levantar os indicadores presentes nos núcleos de significação é a relação destes para permitir a compreensão do objetivo da investigação. Um segundo critério é constituir a presença de conteúdos semelhantes, complementares ou contraditórios, de modo que "[...] os indicadores são fundamentais para 
que identifiquemos os conteúdos e sua mútua articulação de modo a revelar e objetivar a essência dos conteúdos expressos pelo sujeito" (AGUIAR; OZELLA, 2006, p.8).

Com base na experiência como professor secundarista em relação aos conteúdos expressos nos manuais didáticos, nas deliberações da metodologia escolhida e nas expectativas desta pesquisa, propusemos dois núcleos de significação.

No núcleo I, que denominamos por ' $O$ Processo de Inicialização dos Números Irracionais', pretendeu constatar quais números irracionais são veiculados formalmente no material didático do ensino básico e que devem passar por um tratamento didático adequado. Isto pressupôs constatar, nos livros didáticos:

a) como ocorre a introdução conceitual dos irracionais;

b) quais as linguagens utilizadas para apresentação dos elementos básicos dos irracionais;

c) quais os meios didáticos utilizados para o tratamento inicial dos irracionais: atividades manipulativas; uso de softwares, calculadora, planilha e outros meios eletrônicos; realização de simulações; apresentação e interpretação de textos.

$\mathrm{O}$ núcleo II, que denominamos por ' $\mathrm{O}$ desenvolvimento e a amplitude conceitual dos números irracionais', pretendeu relatar se e como o material didático expôs um aprofundamento e tratamento didático dos números irracionais. Este núcleo permitiu verificar se há necessidade de complementos, possibilitando maior amplitude didática e epistemológica dos números irracionais. Este núcleo solicitou do material a ser analisado, um discurso que, além da apresentação formal dos elementos básicos, expusesse os elementos mínimos, necessários e essenciais para a compreensão dos números irracionais. Isto equivale a verificar, nos livros didáticos:

a) se, como e em que medida ocorre a articulação entre as linguagens;

b) se, como e em que medida lidam com informações, métodos, procedimentos e a problemática que surgiu no desenvolvimento histórico do conhecimento matemático. Em particular, será verificada se e como é tratada a Crise dos Incomensuráveis;

c) se há a re-utilização e exploração dos números irracionais nos variados conteúdos e temáticas da Matemática.

A análise e a confrontação dos resultados pontuados e declarados nos dois núcleos permitiu expor o que já está consolidado na apresentação e desenvolvimento dos números irracionais, o que ainda está implícito e não revelado neste processo de inicialização, assim como o que ainda falta. O citado percurso permitiu verificar quais os pontos e em que níveis se torna possível avançar nos patamares intermediários de significação dos irracionais.

Após a descrição dos temas selecionados nos livros didáticos, a análise dos temas envolvendo os números irracionais no livro didático ocorreu em dois sentidos: análise horizontal e vertical.

A análise didática horizontal consistiu em descrever e situar cada um dos três temas elencados anteriormente, nos conteúdos que compõe cada coleção de livro didático. Esta ação foi efetivada no que denominamos 'percurso dos núcleos de significação', que pode ser visualizada no quadro 1. 


\section{INTERFACES DA EDUCAÇÃO}

Quadro 1: Percurso dos núcleos de significação, para a análise de temas presentes no livro didático.

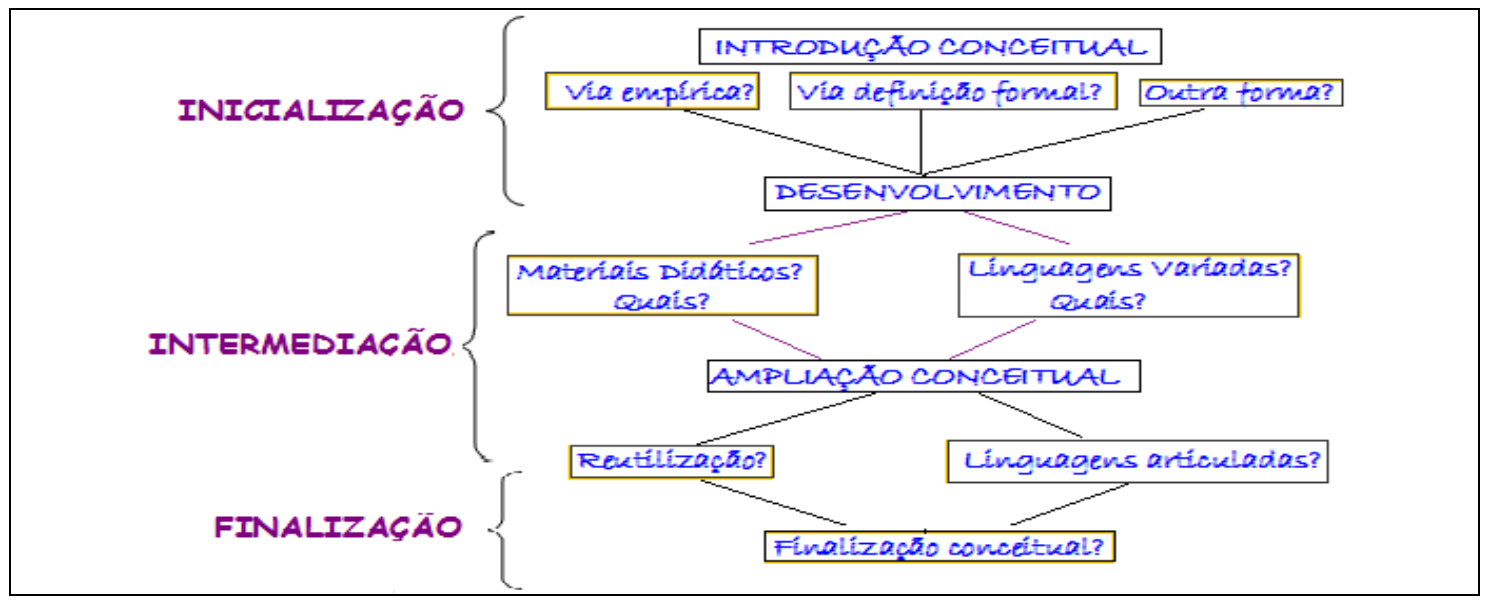

Após a descrição dos componentes apresentados em cada tema, foi feita uma análise vertical, comparando os resultados expressos em cada coleção, com argumentações orientadas pelas propostas aglutinadoras expressas através do percurso dos núcleos de significação.

\subsection{Os critérios de escolha dos livros didáticos}

Justifica-se a busca em livros didáticos por ser material de freqüente adoção pela comunidade escolar e assim, representar objeto de influência considerável no processo de ensino e de aprendizagem. Em muitos casos, é o único material de apoio que os professores utilizam como fonte de conhecimento e para estruturar o trabalho didático na sala de aula.

De modo geral, o livro veicula uma lista de conteúdos a serem apresentados, influenciado por uma sequenciação delimitada e indicada em documentos e orientações oficiais. Este tipo de formato passa a ser considerado como um modo de trabalho didático comum e freqüente para o conhecimento matemático a ser abordado em sala de aula.

Segundo Lüdke e André (1986), a análise de documentos, como o livro didático de ensino básico, permite uma valiosa abordagem de dados num viés qualitativo, revelando aspectos de um tema. Os autores ponderam serem os documentos uma fonte natural estável para retirar evidências e confirmar hipóteses de pesquisa, além de fornecer indícios de situações que poderiam ser exploradas através de outros métodos ou perspectivas.

A investigação nos livros didáticos que empreendemos se situou na visão qualitativa de pesquisa, na forma de uma descrição e na análise didática de alguns temas matemáticos relacionados aos números irracionais, presentes no ensino básico, considerando-se o potencial desses para o desenvolvimento de ideias fundamentais da Matemática.

Devido à existência de diversas coleções de livros didáticos de Matemática para o ciclo básico, no mercado brasileiro, consideramos como critérios a relação de livros aprovados pelo PNLD e no PNLEM, autores com grande tempo no mercado editorial, autores que apresentam formação e interesse em pesquisa acadêmica e livros com grande veiculação a nível nacional.

Vale salientar que não se pretendeu uma avaliação da qualidade do Livro Didático. Antes, a intenção preliminar foi chamar a atenção para uma possível simplificação da apresentação de alguns temas notáveis dos números irracionais no ensino da Matemática. Nesse sentido, a pesquisa empírica se pautou na possibilidade de verificar, em termos 


\section{INTERFACES DA EDUCAÇÃO}

descritivos, se e como alguns temas essenciais referentes aos números irracionais são apresentados e desenvolvidos nos livros-didáticos do ensino básico.

As coleções de livros do Ensino Médio escolhidas para apreciação e análise foram: coleção A, de Imenes e Lellis (2008-2010); coleção B, de Bonjorno; Bonjorno e Olivares (2008); coleção C, das autoras Smole e Diniz (2006-2008); coleção D, de Giovanni e Bonjorno (2009) e a coleção E, de Iezzi et al. (2006).

Quanto aos livros do Ensino Fundamental II, a coleção A considerou que os autores são membros da comunidade de educadores matemáticos e pesquisadores, costumeiramente apresentando inovações no segmento de livros didáticos. Para os critérios da escolha da coleção B, destacamos que os autores são professores de tradição no ensino da Matemática e atuantes no ramo de publicação de livros didáticos.

Considerando-se as coleções de Ensino Médio, a opção pela coleção $C$ levou em consideração a formação e experiência acadêmica das autoras, como também pelas contribuições em formação de professores, material didático e assessorias na educação. Com relação à coleção $D$, ponderamos na grande tradição dos autores no ramo de publicação de livros didáticos e no ensino de Matemática.

Quanto à coleção E, composta por 10 volumes, a escolha recaiu na possibilidade de análise complementar, por apresentar tópicos de Matemática Elementar de modo mais rigoroso e amplo, em relação às coleções usuais. A escolha desta coleção proporcionou outra possibilidade de resposta às questões levantadas, sob um ponto de vista do conhecimento matemático mais aprofundado, com relação às outras duas coleções citadas.

Neste texto, dentre os vários possíveis de análise, nos restringimos a relatar alguns temas essenciais relativos ao Universo dos Números Irracionais: o número PI, o número de Euler e o número de Ouro.

\subsection{Descrição do número PI nos Livros Didáticos}

\subsubsection{Coleção A.}

No livro do $8^{\circ}$ ano, capítulo 13 , no subitem denominado 'Um Toque a Mais', a primeira menção ao valor de PI envolve um texto relatando o trabalho de Arquimedes e a descoberta do empuxo. O texto abre um pequeno parágrafo para citar dois trabalhos de Arquimedes: a fórmula do volume da esfera e de um método para determinar o valor de PI, mas não tece outras considerações a este respeito. Este tipo de abordagem nos faz indagar os motivos que levam a fazer tal opção didática, sem maiores aprofundamentos.

O número PI é introduzido na seção seguinte, pela via empírica. No mesmo livro, no capítulo 14 denominado 'Geometria Experimental', o texto sugere o desenho de uma circunferência com o compasso, contorná-la com um barbante e dividir o comprimento do barbante pela medida do diâmetro, o que resulta num valor de aproximadamente 3,1. Sugerindo que a razão entre o perímetro da circunferência e o diâmetro de uma circunferência é invariável, o que implicitamente representa um salto envolvendo um argumento teórico, sem maiores explicações afirmam que métodos dedutivos permitem obter o valor de PI com maior precisão, expondo o valor $\pi=3,1415926$.

No livro do $9^{\circ}$ ano, capítulo 12, no item denominado 'Círculo e Cilindro', os autores retomam o número PI como sendo a razão entre o perímetro do círculo e o diâmetro correspondente. O livro-texto expõe a inscrição e circunscrição de polígonos regulares a uma 


\section{INTERFACES DA EDUCAÇÃO}

circunferência de raio $\mathrm{R}$, mencionando que para o caso particular de um quadrado, o intervalo é dado por: $2 r^{2}<\pi<4 r^{2}$, processo este representado na figura 1 .

Figura 1: Inscrição e circunscrição de um quadrado

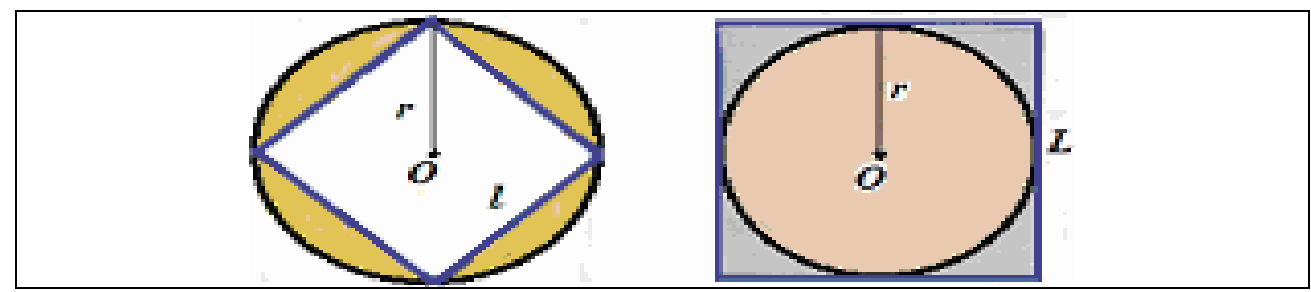

Fonte: Coleção A.

Estendendo o processo, a coleção $A$ cita que o processo consiste em subdividir o número de lados, de modo a obter polígonos inscritos e circunscritos de lados 16, 32, 64 e 128. A seguir, comenta que para um polígono inscrito e circunscrito de 180 lados o valor de PI fica delimitado entre $3,140<\pi<3,144$. Porém, o texto não explica como obter este intervalo, justificado: "Os cálculos são complicados, mas não é necessário que você os faça sozinho. Importante é compreender as ideias” (IMENES; LELLIS, 2008-2010, p. 230).

Também acreditamos que compreender ideias é importante, mas a citada compreensão não pode se restringir somente a um discurso inicial. Este tipo de abordagem poderia ser desenvolvida através de uma situação de aprendizagem utilizando, por exemplo, uma planilha eletrônica e delimitando valores racionais para PI, por excesso e falta, dentro da proposta de inscrição e circunscrição de polígonos regulares a uma circunferência, expresso pelos autores. Isto possibilitaria um caminho trilhando patamares de evolução da significação do conceito de PI, viabilizando o acesso ao conceito teórico de um número irracional, a relação com o infinito e o contínuo, através da operação de aproximação.

A coleção $A$ traz contribuição ao relacionar o número $\pi$ ao infinito, no caso de polígonos inscritos e circunscritos. O texto cita que, ao se dividir pela metade o número de lados do quadrado inicial, se obtém um polígono regular de oito lados, conforme ilustra a figura 2. Este processo, se realizado sucessivamente, leva a um processo infinito.

Figura 2: Construção do octógono regular inscrito, a partir do quadrado

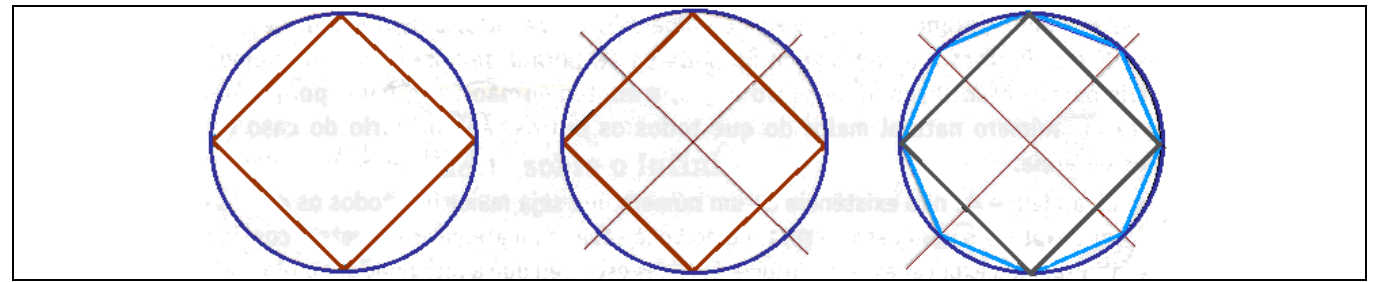

Fonte: Coleção A

Os autores apresentam uma visão inicial do tema infinito, na forma potencial, no livro do $9^{\circ}$ ano, capítulo 12, no subitem denominado 'Um toque a mais'. Partindo da ideia de que, numa praia, há um grande, porém finito número de grãos, os autores ressaltam que no conjunto dos números naturais, a ideia de contagem e de sucessor permite a seguinte afirmação: "a contagem pode não parar porque não existe um número natural maior do que todos os outros, ao contrário dos grãos de areia" (IMENES; LELLIS, 2008-2010, p. 239). 


\section{INTERFACES DA EDUCAÇÃO}

A seguir, o texto apresenta outros contextos geométricos em relação ao infinito na forma potencial: a reta e o segmento de reta. No caso da reta, que não tem começo nem fim, esta pode ser prolongada indefinidamente. Passando para o caso do segmento de reta, os autores discutem um argumento dedutivo: "dados dois pontos diferentes, existe sempre um terceiro ponto entre eles. Essa sentença nos leva a um processo que é infinito" (IMENES; LELLIS, 2008-2010, p. 239).

Por último, no livro da $8^{\circ}$ série, capítulo 13, no item 'Um Toque a Mais', há a exposição de alguns valores obtidos para PI, numa retrospectiva histórica.

\subsubsection{Coleção B.}

No livro do $7^{\circ}$ ano do Ensino Fundamental II, capítulo 1, no item denominado 'Um número irracional especial: $\pi$ ', os autores contam sobre uma simulação, obtendo valores do perímetro (através do uso de barbante) e diâmetro de circunferências, o que indica valores aproximados de PI.

No livro do $8^{\circ}$ ano, capítulo 1, no item denominado 'Números Reais', é apresentado o número PI, através de exemplos, medindo o perímetro do círculo e dividindo-o pelo diâmetro (moeda, latinha cilíndrica e Compact Disk). Em seguida, o texto apresenta a aproximação para duas casas decimais. Por último, os autores relatam a história de Arquimedes e a determinação de um intervalo para PI através de polígonos inscritos e circunscritos.

As deliberações mencionadas são semelhantes ao descrito no livro anterior, porém apresentadas de forma mais simplificadora. Na coleção $\mathrm{B}$, os autores se detêm no viés empírico, que pode até servir como introdução, porém há a necessidade de um trabalho posterior desenvolvendo o conceito de PI.

\subsubsection{Coleção C.}

$\mathrm{Na}$ Unidade 1, volume 1, no desenvolvimento do item 'Números Irracionais', é apresentado o número PI: "Além dos números irracionais representados por radicais, existem outros números irracionais famosos, como o $\pi$ (pi), obtido quando dividimos o comprimento da circunferência de um objeto qualquer e o diâmetro de uma circunferência" (SMOLE; DINIZ, 2006-2008, p. 16). A seguir, o texto expressa que "[...] o valor de PI pode ser representado por uma dízima não-periódica aproximadamente igual a 3,141592654" (SMOLE; DINIZ, 2006-2008, p. 16).

$\mathrm{Na}$ Unidade 4, volume 3, no item denominado 'Flash Matemático', é abordada a temática da quadratura do círculo. A explanação faz uma retrospectiva histórica, com argumentação jornalística, do problema até os dias atuais, citando um recorde atual de casas decimais. Mas não explica o significado ou importância de tal busca de casas decimais, nem remete a natureza irracional do número PI.

Ao final, as autoras se referem ao processo de exaustão que Arquimedes utilizou para inscrever e circunscrever polígonos regulares ao círculo. $\mathrm{O}$ texto cita que o grego "[...] foi feliz, ainda, em mostrar, que o valor de $\pi$ estava entre 3 inteiros e $\frac{10}{71}$ e 3 inteiros e $\frac{10}{70}$, uma aproximação razoável que foi bem aceita durante quase dezoito séculos" (SMOLE; DINIZ, 2006-2008, p. 121). Consideramos que não ficou claro o que se subentende por 'aproximação razoável': é no sentido do cidadão comum ou se referindo ao mundo tecnológico e científico, onde a natureza teórica de PI se mostra relevante? Esta importante situação merece ser 


\section{INTERFACES DA EDUCAÇÃO}

explorada em livros didáticos. Que conjecturas matemáticas, em nível de ensino básico, podem ser encaminhadas para tentar explicar como Arquimedes obteve estes valores?

No texto mencionado, também há referência crítica com relação à corrida para se determinar o maior número de casas decimais de PI: "Tal cálculo é inútil, pois, como observou o astrônomo americano Simon Newcomb (1835-1909), dez casas decimais são suficientemente precisas para dar o valor da circunferência do planeta Terra com erro inferior a uma fração de polegada; e trinta casas decimais dariam a circunferência do universo visível com extraordinária precisão" (SMOLE; DINIZ, 2006-2008, p. 121).

Acreditamos que tal texto responda em parte nossas indagações. Será a corrida para o cálculo de PI inútil? Será que o discurso de um astrônomo, pautado numa necessidade pragmática dos astrônomos, e que trabalhou cerca de cem anos atrás, esgota o problema, a ponto de pode servir de motivo para generalização para todas as áreas científicas? Então, quais os motivos para que a 'corrida do PI' atualmente mobiliza pesquisadores no meio científico?

Uma explicação essencial desta questão advém inicialmente das ciências da computação, as quais utilizam os valores aproximados de PI para testar os próprios modelos computacionais e delimitar precisão dos próprios computadores. Mas por que não se explica isto e se acrescenta o significado de aproximar um número irracional, o que implica mencionar a natureza racional, limitada e finita desta operação, mas que se constitui no único meio de acesso pragmático de um número irracional, cuja natureza é teórica e infinita.

\subsubsection{Coleção D.}

No volume 1, no item Geometria Plana Métrica, no subitem Circunferência, é representado o número PI, numa analogia com a roda de uma bicicleta, pela definição de perímetro de uma circunferência. "Você já aprendeu que o comprimento de qualquer circunferência é dado pela fórmula $\mathrm{C}=2 \pi \mathrm{r}$, sendo $\pi=3,14151 \ldots$, um número irracional" (GIOVANNI; BONJORNO, 2009, p. 39).

O livro-texto apresenta vários exercícios para uso da expressão $\mathrm{C}=2 \pi . r$, sendo solicitado considerar "[...] $\pi=3,14$ uma aproximação racional com duas casas decimais" (GIOVANNI; BONJORNO, 2009, p. 39).

\subsubsection{Coleção E}

Quanto ao número PI, os autores apresentam-no no livro 9, capítulo XVII: "A razão entre o perímetro do círculo e seu diâmetro é um número constante representado por $\pi$ " (IEZZI et al., 2006, p. 230).

A seguir, para “[...] ter uma noção do número PI” (IEZZI et al., 2006, p. 231), apresentam uma tabela de tripla entrada, contendo as razões $\frac{p_{i}}{2 R} \mathrm{e} \frac{p_{c}}{2 R}$, onde $p_{\mathrm{i}}$ representa $\mathrm{o}$ perímetro interno ao círculo de raio $\mathrm{R}$ e $\mathrm{p}_{\mathrm{c}}$ representa o perímetro externo ao círculo de raio $\mathrm{R}$. O livro não ilustra como surgem estas relações, simplesmente situam o valor de PI entre os extremos $3,14145<\pi<3,14188$, apresentação que não justifica o discurso dos autores "[...] assim vai 'nascendo' o número PI" (IEZZI et al., 2006, p. 231). 


\section{INTERFACES DA EDUCAÇÃO}

\subsection{Análise e Síntese do número PI nos livros didáticos}

Considerando-se o núcleo I (O Processo de Inicialização dos Números Irracionais), as coleções $A$ e $B$, do Ensino Fundamental, fazem a introdução conceitual do número PI pela definição clássica: razão entre o perímetro e o diâmetro de uma circunferência, num viés geométrico e empírico.

Quanto às obras do Ensino Médio, as coleções $C$ e $D$ situam um contexto dual: pelo modo empírico e pela definição. Por último, a coleção $E$ introduz a apresentação formal, sem acesso ao empírico.

Com relação ao uso de linguagens, os livros didáticos adotam a abordagem numérica, algébrica e geométrica. Quanto aos meios didáticos, os livros do Ensino Fundamental II se restringem ao uso de materiais empíricos, conforme se ilustra no quadro 2.

Quadro 2: O uso de meios didáticos para acessar o número PI.

\begin{tabular}{|c|c|c|c|c|}
\hline Coleção A & Coleção B & Coleção C & Coleção D & Coleção Extra \\
\hline $\begin{array}{l}\text { Compasso; simulação } \\
\text { com barbante e trena. }\end{array}$ & $\begin{array}{l}\text { Compasso; simulação } \\
\text { com barbante e trena. }\end{array}$ & --- & -- & -- \\
\hline
\end{tabular}

Focando o núcleo II, os livros não fazem articulação entre as linguagens. Isto promove uma excessiva simplificação ao estudo de PI, o que culmina em lidar com poucas referências, acentuando o livro didático como relator de fatos, sem remeter a maiores explicações.

A constatação fica elucidada ao observamos a exposição do processo de inscrição e circunscrição de polígonos a um círculo, delimitando um intervalo racional para o número $\pi$. Todos os livros analisados, com exceção da coleção $D$, fazem um breve relato do processo. Porém, a coleção $A$ apresenta disposição em ampliar o discurso. Para isso, além de fornecer uma explicação inicial, a citada obra calcula a área do quadrado inscrito e circunscrito para a primeira parte do processo. Entretanto, o texto se limita a trabalhar uma possibilidade, não desenvolvendo as demais etapas do processo, justificando que os cálculos são complicados.

Porém, existem meios didáticos de acessar tal processo. Um exemplo disso são as planilhas eletrônicas, que associadas à questão de aproximação ampliariam o repertório numa sequência que disponibilizaria tanto o discurso textual como a linguagem matemática específica. Vale ressaltar que o uso de recursos informáticos “[...] permite recuperar conceitos matemáticos ou mesmo facilitar a própria construção de muitos conceitos por meio de uma atribuição mais clara e visível de significação. E a consistência da construção significativa do conhecimento pode ser observada" (BONOMI, 2004, p. 7).

Em síntese, as apresentações são simplificadoras e não permitem significar a natureza do número PI, como um número irracional. A utilidade de inscrever e circunscrever polígonos à circunferência permitiria ilustrar o papel das aproximações, a discussão do processo infinito, explorar a aproximação como um recurso de acesso ao número irracional e até delimitar valores numéricos que introduzissem a noção de aproximação. Uma boa aproximação é aquela que sempre pode ser melhorada e corresponde a uma necessidade pragmática. A natureza do número irracional é teórica e a aproximação consiste num recurso didático para se iniciar a discussão de tal natureza.

Em síntese, concluímos que os livros didáticos realizam uma apresentação simplificadora, que trunca o 'percurso dos núcleos de significação', não permitindo elucidar a natureza do número PI, como um número irracional.

A utilidade de inscrever e circunscrever polígonos à circunferência permitiria explorar um processo infinito onde a aproximação seria o recurso de acesso ao número irracional PI, 


\section{INTERFACES DA EDUCAÇÃO}

que dialeticamente poderia ampliar a noção de aproximação. Uma boa aproximação é aquela que sempre pode ser melhorada e corresponde a uma necessidade pragmática.

\subsection{Descrição do número de Euler nos Livros Didáticos}

\subsubsection{Coleções A e B}

Não encontramos menção.

\subsubsection{Coleção C}

Quanto ao número de Euler (e), este é apresentado ao final da Unidade 8, p. 234-235, no volume 1, no item denominado Sistema de Logaritmos. Como apêndice ao tema, o texto cita que existe um sistema de logaritmos na base e', descrevendo o valor aproximado de 2,7182818, sem citar que este representa um número irracional. Ainda, o texto relata que os logaritmos na base 'e' são denominados logaritmos naturais ou neperianos, em homenagem a John Napier. Mas qual a relação da denominação 'natural' com o número de Euler? E por que apresenta o valor aproximado?

\subsubsection{Coleção D}

O número de Euler (e) é apresentado no item logaritmos, descrevendo-o como sendo 2,718281828....., um valor aproximado referente ao sistema de logaritmos na base e'. Não há menção do número de Euler ser irracional. Notamos que o modo escolhido pelo livro para o registro dos dígitos (1828) pode induzir o aluno a acreditar que existe regularidade no número de Euler. O texto ainda se refere ao número de Euler pela definição $\mathbf{e}=\lim _{\mathrm{x} \rightarrow 0}(1+x)^{1 / x}$.

Por último, o manual ilustra cinco aplicações de leis utilizando o valor do número de Euler e relacionando a curva de aprendizagem (p. 236), o decaimento radioativo (p. 252), o crescimento de populações (p. 257), o crescimento de uma mancha de petróleo devido ao vazamento de uma plataforma (p. 258) e a estimativa do método de carbono 14 (p. 277).

\subsubsection{Coleção E}

No volume 2, intitulado 'Logaritmos', no capítulo II, dedicado a Função Exponencial, os autores expõem a construção do gráfico da função $\mathrm{f}(\mathrm{x})=e^{x}$, onde 'e' é apresentado como o número de Euler, dado por $\mathbf{e}=\lim _{\mathrm{x} \rightarrow 0}(1+x)^{1 / x}, \operatorname{com} \mathrm{x} \in \mathrm{R}$. O texto contém uma tabela ilustrando alguns valores de $\mathrm{x}$, no intervalo [-3;3] e localizados no plano cartesiano, o que acarreta na exposição gráfica. É destacado que, para $\mathrm{x}=1$, o valor numérico da função $\mathrm{f}(\mathrm{x})=e^{x}$ corresponde ao número de Euler: $\mathbf{e}=2,7183$. A introdução formal tem contribuição limitada pelo uso de linguagem algébrica e exposição de conceitos mais sofisticados, principalmente ligados ao limite de uma função, não abordados no Ensino Médio. 


\section{INTERFACES DA EDUCAÇÃO}

No volume 8 (Limites, Derivadas e Noções de Integral) os autores também abordam o número de Euler. Após a apresentação de um teorema que introduz a função $\mathrm{f}(\mathrm{x})=\left(1+\frac{1}{\mathrm{n}}\right)^{n}$, no âmbito de $\mathrm{N}^{*}$, o número de Euler é definido como conseqüência do teorema citado, ou seja, $\lim _{\mathrm{x} \rightarrow+\infty}\left(1+\frac{1}{\mathrm{n}}\right)^{n}=e$, denominado o limite exponencial fundamental.

Há menção do número de Euler ser um número irracional, cujo valor aproximado é 2,7182818284. Por último, seguem-se os habituais exercícios de aplicação, cujos resultados envolvem potências do número de Euler. Esta exposição limita o acesso ao significado do tema: quem não domina a sintaxe matemática não tem acesso aos significados

No volume 2, intitulado 'Logaritmos', no capítulo III, após a introdução da definição canônica de logaritmos, e das conseqüências da definição, é apresentado o item 'Sistemas de Logaritmos'. No $5^{\circ}$ parágrafo, é relatado que "[...] o sistema de logaritmos neperiano é o sistema de base e ( $\mathrm{e}=2,71828 \ldots$ [um] número irracional), também chamado de sistema de logaritmos naturais. $\mathrm{O}$ nome neperiano vem de John Neper [...]. O nome natural se deve ao fato de que no estudo dos fenômenos naturais geralmente aparece uma lei exponencial de base e" (IEZZI et al., 2006, p. 55).

\subsection{Análise e Síntese do número de Euler nos livros didáticos.}

Este irracional é apresentado nas coleções $A$ e $B$, de Ensino Médio, no tópico logaritmos, fazendo referência ao fato de ser uma base natural e ter um valor aproximado, sem maiores explicações. A coleção $E$ introduz o número de Euler no volume intitulado 'Limites'. A coleção $D$ e a coleção $E$ utilizam a definição formal, não acrescentando significado a brevíssima apresentação do número de Euler. O destaque fica para a coleção $C$, a qual apresenta cinco exercícios envolvendo o número de Euler, por via instrumental de aplicação de fórmula dada no enunciado. Da forma veiculada, as coleções pouco ilustram o que representa o número de Euler, ficando a apresentação deste tema restrita ao núcleo I.

\subsection{Descrição do número de Ouro nos Livros Didáticos}

\subsubsection{Coleções A e B}

Não encontramos menção.

\subsubsection{Coleção C}

A unidade 1 faz menção ao segmento áureo, representado pela letra grega 'fi' $(\phi)$, como a razão entre lados de um retângulo, muito utilizado no campo artístico (figura 3). 
Figura 3: Obtenção do segmento áureo

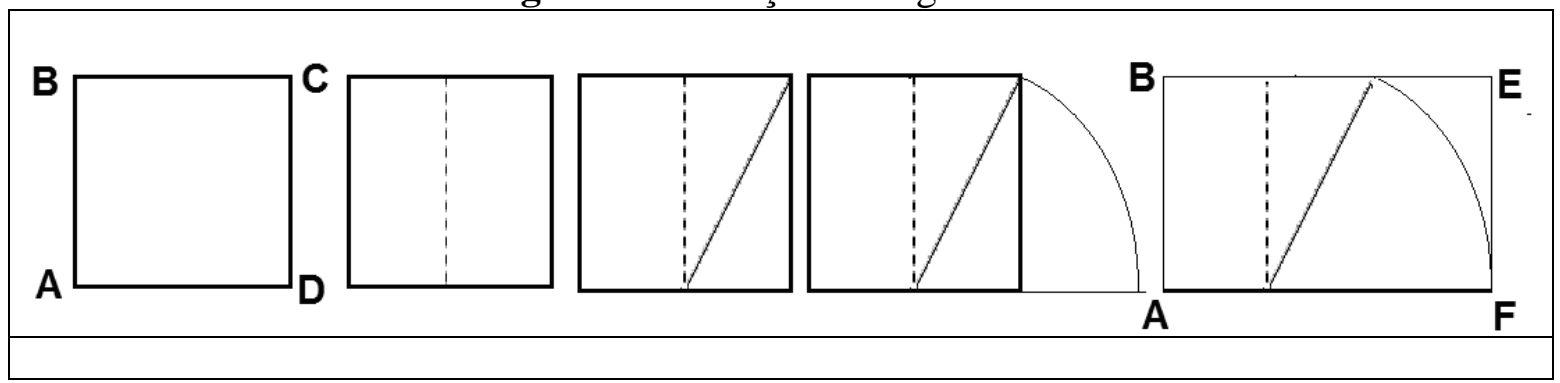

Fonte: In. SMOLE; DINIZ (2006-2008, p.16)

O livro-texto expõe a construção do referido retângulo, e, a partir de argumentos geométricos, aplica o teorema de Pitágoras, obtendo o valor $\phi=\frac{1+\sqrt{5}}{2}$ (figura 4).

Figura 4: Obtenção do segmento áureo

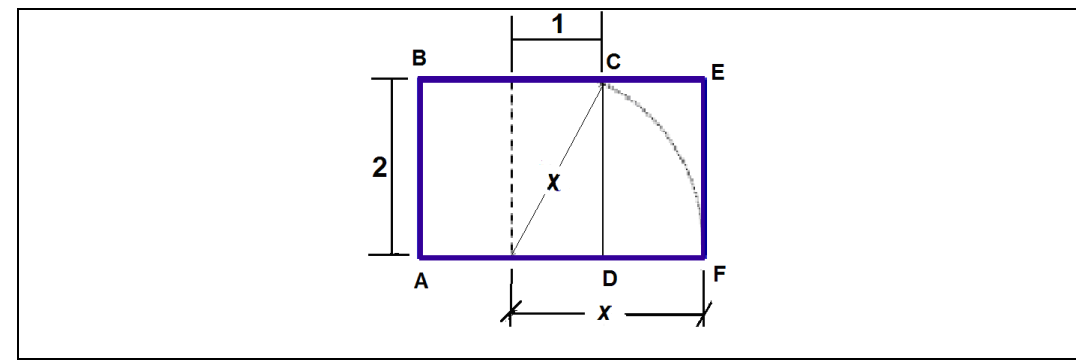

Fonte: In. SMOLE; DINIZ (2006-2008, p.16).

O livro retoma a questão do segmento áureo ao expor a seqüência de Fibonacci, utilizando o conhecido problema da reprodução de coelhos, a partir de um único casal, que em cada mês gera um novo casal, que se torna fértil a partir do segundo mês de vida.

As variações de linguagens utilizadas para expor o número de ouro se constituem em importante contribuição, mas não são aproveitadas para explicar a natureza das aproximações, do processo infinito que pode ser relacionado e nem aprofundam o contexto teórico deste número irracional.

\subsubsection{Coleção D}

Não encontramos menção ao número de ouro.

\subsubsection{Coleção E}

O segmento áureo surge no livro 9, capítulo XVII, intitulado 'Polígonos Regulares', na definição formal $\frac{x}{a}=\frac{a-x}{x}$, onde $\frac{x}{a}$ representa a razão áurea. Os autores aplicam um tratamento algébrico à definição, obtendo $x^{2}+a \cdot x-a^{2}=0$, e expõe o resultado $x=\frac{\sqrt{5}-1}{2} \cdot a$, sem posteriores comentários. 
O tipo de abordagem desta coleção utiliza várias linguagens, porém todas acessadas de modo formal. Este aspecto teórico restringe o significado, pois privilegia a sintaxe e não conduz para a elucidação dos termos e dos conceitos envolvidos, o que poderia ser realizado por meio de uma abordagem didática que expresse ideias.

\subsection{Análise e Síntese do número de Ouro nos livros didáticos.}

O referido irracional é apresentado somente nas coleções $\mathrm{C}$ e E. No quadro 3 indicamos as observações referentes ao núcleo I (O tratamento didático dos números irracionais).

Quadro 3: A abordagem introdutória para o número de Ouro

\begin{tabular}{|c|c|c|}
\hline Coleção C & Coleção D & Coleção E \\
\hline $\begin{array}{l}\text { A introdução conceitual do número de } \\
\text { ouro ocorre pela representação figural, a } \\
\text { partir da construção de um quadrado. } \\
\text { Posteriormente, é dado um tratamento } \\
\text { algébrico para se determinar o valor de } \phi \text {. } \\
\text { São também apresentados alguns } \\
\text { contextos de aplicação. }\end{array}$ & Não há menção & $\begin{array}{l}\text { A introdução conceitual do número de } \\
\text { ouro ocorre pela representação figural, } \\
\text { pela definição } \frac{x}{a}=\frac{a-x}{x} \text {, e em } \\
\text { manipulações algébricas, de modo a } \\
\text { obter } \phi=\frac{1+\sqrt{5}}{2} \text {. }\end{array}$ \\
\hline
\end{tabular}

Vale destacar a utilização de apresentação empírica no tratamento da coleção $C$, antagônica à introdução teórica da coleção $E$. Porém, a coleção $C$ avança no percurso de significação dos núcleos em direção a um desenvolvimento conceitual, pelo tratamento algébrico efetuado para se determinar a razão áurea, retornando, em seguida, a via empírica, apresentando os contextos das artes e a sequência de Fibonacci.

A coleção $C$ apresenta variedade de linguagens e meios didáticos: utilização de textos jornalísticos, representações figurais, uso de cálculos aritméticos, algébricos e figuras geométricas, mobilizando diversos registros para a apresentação do tema. Porém, a predominância pelo empírico limita o desenvolvimento deste tema, não oportunizando a ampliação conceitual e significação do número irracional envolvido.

A coleção $C$ apresenta o número de ouro com maior articulação entre linguagens que a apresentação de PI e, principalmente, ao número de Euler, o que possibilitou uma maior incursão no percurso dos núcleos de significação.

\section{Considerações Finais}

Como análise inicial, num olhar voltado a aspectos desenvolvidos as obras, observa-se um esforço didático das coleções em trabalhar os temas delineados e adequá-los a faixa de ensino que se propõe.

Realizando uma síntese da abordagem do número PI, o número de Euler e o número de ouro, observamos nas coleções a apresentação de algumas informações e sugestões de procedimentos surgidos a partir do desenvolvimento histórico do conhecimento matemático. Porém, as coleções não avançam para ilustrar, articular e explicar o discurso que sugerem, em face da complexidade e importância destes tópicos essenciais ao ensino básico.

É peculiar a falta de uso de meios eletrônicos (calculadora e planilhas eletrônicas) para viabilizar algumas situações de ensino que pudessem caracterizar tanto o número $\pi$ como $o$ 


\section{INTERFACES DA EDUCAÇÃO}

número de Euler, articulando-os aos diversos conhecimentos matemáticos e científicos. Vale relembrar que muitos alunos desconhecem a gênese e significado dos símbolos estampados no teclado das calculadoras, tal como o número $\pi$ e o número de Euler, apontados em Machado (1994).

Os livros didáticos, não elucidando o contexto das calculadoras eletrônicas, reduzem a possibilidade de compreensão da natureza dos números irracionais. $\mathrm{O}$ uso da calculadora e do computador em sala de aula é um recurso que permite explorar o entendimento dos números irracionais, conciliando a leveza e a rapidez em:

[...] cálculos sem o peso da repetição de algoritmos, que, sem a tecnologia, precisariam ser executados manualmente pelos alunos ou pelo professor. Toda essa parte é rapidamente solucionada. [...] Uma preocupação sempre presente não é apenas aquela da resolução de determinados problemas, mas também a observação, a análise crítica e a significação dos resultados (BONOMI, 2004, p. 7).

Torna-se necessário um trabalho didático de esclarecimento e encaminhamento para compreender que os resultados aproximados ao acessar as teclas das calculadoras eletrônicas representam números racionais finitos, como observamos nas coleções, para acessar o número PI. A explicação reduzida ou não realizada pode induzir e iludir os alunos no trato dos números irracionais como se fossem decimais finitos e, portanto, números racionais.

Ainda com relação às aproximações, após a enunciação dos resultados com uma, duas ou até três casas decimais, os livros didáticos citam que números irracionais, como o caso de PI, possuem infinitas casas decimais e não-periódicas, mas não justificam esta declaração. Quais os argumentos que garantem a não-periodicidade nos exemplos citados dos livros didáticos analisados? Ou ainda, quais fatos asseguram que o mesmo possui infinitas casas decimais?

Os livros didáticos fazem menção sobre o resultado mostrado pelas calculadoras eletrônicas e mencionam que os irracionais apresentam infinitas casas decimais e nãoperiódicas. Mas aí há um salto, pois as calculadoras não podem mostrar infinitas casas, e nem os computadores, por uma limitação de armazenamento na memória. Esta questão nem é discutida pelos textos.

Nas coleções, observamos a falta de uma abordagem situando e significando tais números como irracionais: os aportes teóricos são introduzidos ora via pseudoempírica, relatando situações e contextos práticos e, posteriormente, pela via formal, porém sem articulação entre estes modos. Deste modo, sem a construção de modos didáticos de exploração e articulação presente nesta polaridade, ficam restritas as possibilidades de significar estes temas no Ensino Médio.

Considerando-se o viés empírico, optado em algumas coleções (A, B e C), em geral houve a exploração e uso de algumas linguagens matemáticas, mas que pouco dialogaram entre si. A falta de opções didáticas que promovam o intercâmbio entre linguagens não permite trilhar caminhos que avancem no 'percurso de significação' dos números irracionais.

Pela via oposta, nos livros que optaram pela introdução formal (coleção D e extra), via definição, observamos que a linguagem geralmente utilizada fica restrita ao registro algébrico, com posterior exemplificação situada no registro aritmético. Esta limitação de exploração de linguagens também trunca o desenvolvimento de utilização de outros modos, como a linguagem natural, assim como pela diversificação de contextos e recursos que possibilitariam o acesso do significado dos objetos. 
Após o treinamento das definições, as obras utilizadas geralmente recorrem a exercícios de fixação, explorando o modo sintático de escrita matemática, porém sem encaminhar situações que enriqueçam o repertório e explorem os significados.

Também destacamos outra circunstância: os temas pesquisados aparecem em momentos pontuais no livro didático. Lembrando que significar um conhecimento remete a estabelecer uma rede de relações, a escassa retomada dos números irracionais em outros momentos no desenrolar dos assuntos tratados nos livros didáticos pesquisados não colabora para tecer conexões entre os assuntos que delineamos como o corpo de conhecimentos da Matemática.

Em síntese, as constatações destacadas nos livros didáticos somente iniciam um percurso de introdução aos números irracionais, vinculados ao notável número PI, com algumas poucas menções a outros números irracionais, o que limita a compreensão do número irracional, no ciclo básico.

\section{Referências bibliográficas}

AGUIAR, W. M. J.; OZELLA, S. Núcleos de significação como instrumento para a apreensão da constituição dos sentidos. Psicologia: ciência e profissão, Brasília, v.26 n.2, jun. 2006. BOFF, D. S. A construção dos números reais na escola básica. Dissertação de Mestrado Profissionalizante. Universidade Federal do Rio Grande do Sul, Porto Alegre, 2006.

BONJORNO, J. R.; BONJORNO, R. A.; OLIVARES, A. Matemática: Fazendo a Diferença. São Paulo: Editora FTD, 4 volumes, PNLD 2008.

BONOMI, M. C. Ensino de Matemática: novas tecnologias, novos problemas. SEMA, 2004. . Os números irracionais e as calculadoras. São Paulo: SEMA, 1 sem. 2008.

BOYER, C. B. História da Matemática. 9. ed. São Paulo: Editora Edgard Blücher, 1991.

BRASIL. Secretaria da Educação Fundamental. Parâmetros Curriculares Nacionais: $3^{\circ}$ e $4^{\circ}$ ciclos do Ensino Fundamental:Matemática. Brasília: MEC/SEF. 1998.

COELHO, M. P. F. A Multiplicação de números inteiros relativos no 'ábaco dos inteiros': uma investigação com alunos do . $^{\circ}$ ano de escolaridade. 2005,.Dissertação (Mestrado em Educação), Universidade do Minho, Braga.

FISCHBEIN, E.; JEHIAM, R.; COHEN, D. The Concept of Irrational Numbers in HighSchool Students and Prospective Teachers. Educational Studies in Mathematics. jul. 1995, v. 29, n. 1, p. 29-44. Disponível em: <http://www.jstor.org/stable/3482830>. Acesso em: 12 dez. 2011.

GIOVANNI J. R.; BONJORNO, J. R. Matemática Completa. São Paulo: Editora FTD, 3 volumes, PNLEM 2009.

KARLSON, P. A Magia dos Números. Rio de Janeiro: Editora Globo, 1961.

IEZZI, G. et al. Fundamentos da Matemática Elementar. 10 volumes, São Paulo: Editora Atual, 2006.

IMENES, L. M.; LELLIS, M. Matemática para Todos. São Paulo: Editora Scipione, 4 volumes, PNLD 2008-2010.

LÜDKE, M.; ANDRÉ, M. E. D. A. Pesquisa em Educação: Abordagens Qualitativas. São Paulo: Editora Pedagógica e Universitária, 1986.

MACHADO, N. J. Matemática e Realidade. 3. ed. São Paulo: Editora Cortez, 1994.

REZENDE, W. M. O Ensino de Cálculo: Dificuldades de Natureza Epistemológica. 2003.

Tese (Doutorado em Educação). Universidade de São Paulo, São Paulo. 


\section{INTERFACES DA EDUCAÇÃO}

RIPOLL, C. C. A Construção dos Números Reais nos Ensinos Fundamental e Médio.

UFRGS, 2001.

SANTOS, J. C. Números reais: um desafio na educação básica. Centro de Estudos Gerais, Instituto de Matemática. Niterói, 2007.

SÃO PAULO. Proposta Curricular do Estado de São Paulo: Matemática/ Ensino Fundamental (ciclo II) e Médio. São Paulo: SEE, 2008.

SILVA, A. L. V. Números reais no ensino médio: identificando e analisando imagens conceituais, 2011a. Tese (Doutorado em Educação). Pontifícia Universidade Católica do Rio de Janeiro, Rio de Janeiro.

Números reais no ensino médio. 2011b. Disponível em:

<http://www.anped.org.br/app/webroot/34reuniao/images/trabalhos/GT19/GT19-

1115\%20res.pdf $>$. Acesso em: 20 dez. 2011.

SMOLE, K.; DINIZ, M. I. Matemática: Ensino Médio. São Paulo: Editora Saraiva, 3

volumes, PNLEM 2006-2008.

SOUTO, A. M. Análise dos Conceitos de Número Irracional e Número Real em Livros

Didáticos da Educação Básica, 2010. Dissertação (Mestrado em Ensino de Matemática). Instituto de Matemática, Universidade Federal do Rio de Janeiro, Rio de Janeiro.

VOSKOGLOU, M; KOSYVAS, G. A study on the comprehension of irrational numbers. Quaderni di Ricerca in Didattica (Mathematics), n. 21, 2011. Disponível em:

<http://math.unipa.it/ grim/Voskoglou\%20Kosyvas_Q21.pdf>. Acesso em: 11 ago. 2011. 